\title{
ORWARE: an aid to environmental technology chain assessment
}

\author{
G. Assefa *, A. Björklund, O. Eriksson, B. Frostell \\ Division of Industrial Ecology, Royal Institute of Technology, S-10044 Stockholm, Sweden
}

\begin{abstract}
This article discusses the ORWARE tool, a model originally developed for environmental systems analysis of waste management systems, and shows its prospect as a tool for environmental technology chain assessment. Different concepts of technology assessment are presented to put ORWARE into context in the discussion that has been going for more than two decades since the establishment of the US Congressional Office of Technology Assessment (OTA). An even-handed assessment is important in different ways such as reproducibility, reliability, credibility, etc. Conventional technology assessment (TA) relied on the judgements and intuition of the assessors. A computer-based tool such as ORWARE provides a basis for transparency and a structured management of input and output data that cover ecological and economic parameters. This permits consistent and coherent technology assessments. Using quantitative analysis as in ORWARE makes comparison and addition of values across chain of technologies easier. We illustrate the application of the model in environmental technology chain assessment through a study of alternative technical systems linking waste management to vehicle fuel production and use. The principles of material and substance flow modelling, life cycle perspective, and graphical modelling featured in ORWARE offer a generic structure for environmentally focused TA of chains and networks of technical processes.
\end{abstract}

(C) 2004 Elsevier Ltd. All rights reserved.

Keywords: Material flow analysis; Substance flow analysis; Life cycle assessment; Technology assessment; Waste management

\section{Introduction}

The driving force of technical inventions has been to improve the quality of life. However, the negative impacts of technology were recognised well before the concept of sustainable development was formulated in growth-development discussions. Hence, a variety of methods have been developed for evaluating the impacts of technical processes and products on a number of aspects of human well-being and the environment. An approach with a very broad scope is technology assessment (TA). One institution that contributed to the early development of TA was the US Congressional Office of Technology Assessment (OTA). The office was founded in 1972 to study technology change with the purpose to provide early indications of the probable beneficial and adverse impacts of the applications of technology.

The United Nations Environmental Program (UNEP) broadly defines TA as "a category of policy

\footnotetext{
* Corresponding author. Tel.: +46-8-790-9331; fax: +46-8-7905034.

E-mail address: getachew@ket.kth.se (G. Assefa).
}

studies, intended to provide decision-makers with information about the possible impacts and consequences of a new technology or a significant change in an old technology. It is concerned with both direct and indirect or secondary consequences, both benefits and disadvantages, and with mapping the uncertainties involved in any government or private use or transfer of a technology. TA provides decision-makers with an ordered set of analysed policy options, and an understanding of their implications for the economy, the environment and the social, political and legal processes and institutions of society" [1].

Discussions regarding TA in the literature tend to point out the absence of consensus on different issues related to operating TA. Ludwig [2] and van Eijndhoven [3] have described the controversy around the concept as "TA dilemma". The former, however, went on to say that solutions to global problems which threaten the notion of sustainable development can only be realised through technology, and the indispensability of TA comes due to the need to avoid unwise and unfounded decision in selecting the right technology [2]. Some of such discussions in the literature can be summarised under three points: 
1. Is there a generic methodology for performing TA?

2. What issues should be covered in TA?

3. What known concepts and tools are applied in TA?

When the OTA was closed by the Congress in 1995 after 23 years of service that produced a number of TA reports, one of the issues raised by its critics was related to methodology expressed as lack of methodology [2]. In the words of an insider to OTA, "OTA had difficulty in developing and sharing successful approaches to assessment, either at the tactical level of specific techniques or at the conceptual level" [4]. The tactical level refers to specific data collection and research methods. The conceptual level also called midlevel methodology provides a common conceptual frame of reference for many studies.

Durbin and Rapp pointed to this problem as "vague scientific and methodological status of TA" [5]. With regard to disciplinary organisation of impact criteria, TA suffered from relatively poor co-ordination, integration, and overall balance [6].

Technology assessment has also been criticised as "non-paradigmatic" and therefore, by inference, not cumulative [7]. In a survey of actual TA projects in the United States, Rossini et al. [8] found that TA practitioners, at least in the first years, seldom used any of the quantitative techniques that had been widely advocated in the theoretical literature. Quantitative tools were not favoured. In fact specialists preferred to rely on their own judgements and intuition in the selection of approaches and in the design of the TA [9]. These problems had a surpassing impact on the credibility and reproducibility of TA studies. A well-defined paradigm would offer a common language, making it easier to compare different TA studies than is the case with intuitive practices.

On the other end of the discussion, there were those who object the attempt to have a common methodology labelling it as "reducing TA to a formula" [10]. While recognising the merit of allowing each specific TA to determine the methodology, this claim should not overshadow the importance of developing a methodology on the basis of which TA studies can be carried out on a comparative level.

Attempts have been made to categorise and explain the aims of different types of TA. The Institute for Technology Assessment and Systems Analysis (ITAS) in Karlsruhe distinguishes between three types of TA with different starting points: project-induced, probleminduced and technology-induced TA [11]. Four types of TA with different objectives can be identified: awareness, strategic, constructive, and back casting, all of which may aim at either analysis or intervention [12].

Over the years, TA has assumed different definitions of varying emphasis. According to the European Chemical Industry Council (CEFIC), TA originally concerned itself with the assessment of the political and socio-economic impacts of new technologies, but now includes environmental dimensions as well [1]. There is also a recent trend towards TA focusing primarily on environmental impacts, as is promoted by a UNEP program called Environmental Technology Assessment (EnTA). As defined by this program, EnTA is a process that can assist decision-makers in making informed choices that are compatible with sustainable development by examining and describing the environmental implications of new technologies. It also provides information that allows public policy makers, NGOs, and the general public to be better informed about technology choice decisions [13].

The extent of issues covered in TA naturally requires that a range of tools be applied. In the case of EnTA, environmental management tools such as environmental impact assessment (EIA), life cycle assessment (LCA) and risk assessment (RA) are considered by UNEP to be similar but separate from TA [13], while CEFIC regards them as part of a broad range of TA tools [1]. A relatively structured picture of how different tools and methods called "instruments of TA" relate to each other is given [2]. These include EIA, LCA, environmental management and audit scheme (EMAS), and ecobalance (EB).

In light of what is said above about methodology, issues, and tools of TA, a model concept which may contribute to the development and practice especially of environmentally focused TA is introduced. Since 1993, a computerised model for systems analysis of waste management systems, known as ORWARE, has been developed in Sweden. It is characterised by (1) material and substance flow modelling of the technology system, (2) life cycle perspective and (3) quantification of potential environmental and economic impacts. An important feature is also the graphical model implementation, which gives an intuitive picture of the modelled system. If generalised, these basic principles offer the generic structure of a tool for system identification and analysis of potential impacts of other technology systems in TA with environmental focus. Particularly interesting and useful would be the application of such a tool to chains or networks of linked technologies. To emphasise the close connection to the concept of chain analysis, the term "environmental technology chain assessment" is tentatively introduced to capture the purpose and scope of such a tool.

\section{Objectives}

We argue that the principles of material and substance flow modelling, life cycle perspective and graphical modelling featured in ORWARE offer a generic structure for environmentally focused TA of chains 
and networks of technical processes. The purpose of this article is to show how tools such as ORWARE that combine different tools of systems analysis can contribute to the improvement of TA. To this end, the model is presented and described on the basis of standard tools used in developing it. The application of the model as a tool for environmental technology chain assessment is illustrated by using a study of alternative technical systems linking waste management to vehicle fuel production and use.

\section{Methodology}

ORWARE is a systems analysis model for calculating the impacts of municipal waste management systems (fully described in e.g. [14]). Initially, the model focused on environmental impact and energy turnover of handling organic (biodegradable) wastes, hence the acronym ORWARE (ORganic WAste REsearch). Later, it has been further developed to include all types of non-hazardous municipal solid wastes and to incorporate economic models. Its aim is to enable quantified and systematic comparisons of different solutions of waste management. Standard tools are combined to render ORWARE its present form and scope namely material/substance flow analysis (MFA/SFA), LCA and life cycle costing (LCC) all of which have been classified as chain analysis tools. Chain analysis tools determine the overall environmental effects of any specific change to a particular physical system by taking into account indirect effects in the chains of production and consumption involved. Thus, environmental considerations encompass the whole material and energy supply chain $[15,16]$.
Material/substance flow analysis (MFA/SFA) is used in modelling the processes of the system $[16,17]$. This enables quantitative calculation of flows in terms of materials and substances, flows of pollutants and of products. Mass balances of selected substances, or groups of substances, are calculated throughout the treatment system, giving the opportunity of identifying environmental improvements related to different substances. On the basis of substance and material flows, energy turnover, costs and revenues are also calculated.

Life cycle assessment (LCA) methodology is involved in determining the model system boundaries and in the assessment of potential ecological aspects [18]. The system boundary includes the entire chain of processes connected to the waste management system both directly and indirectly. This is characteristic of the cradle-to-grave perspective of LCA. Directly related are waste collection and transport, incineration, landfill, compost, anaerobic digestion, sewage treatment, plastic and cardboard recycling, and thermal gasification. These processes constitute the so-called core system. Indirectly related are up-stream processes that provide resources to the core system, such as electricity generation and fuel production, and down-stream processes that utilise waste-derived products, for instance utilisation of organic fertiliser and waste-derived vehicle fuel. Up-stream and down-stream processes are parts of the so-called enlarged system (Fig. 1).

Comparison between different waste management alternatives is done by scenario comparison. This comparison is justified by specifying functional units. A functional unit is a measure of the performance of the functional output of a system [19]. Since the scenarios

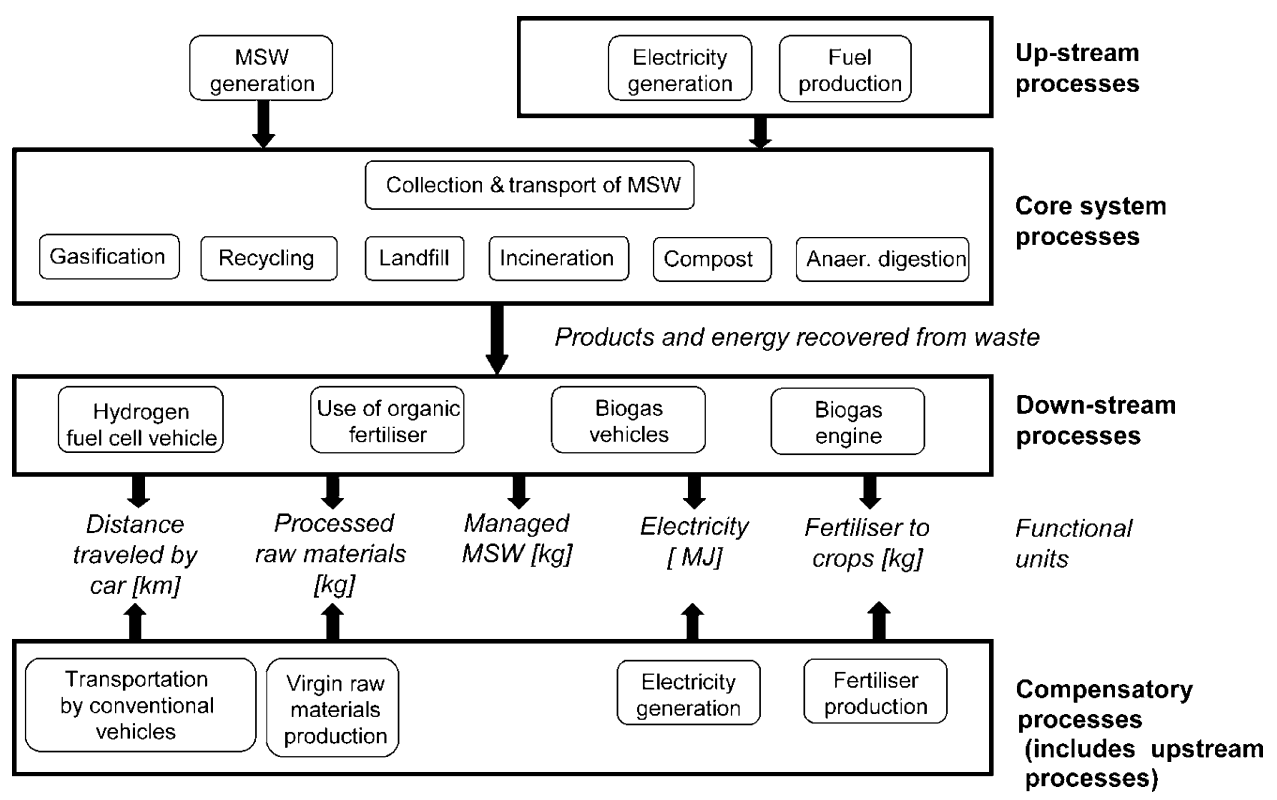

Fig. 1. Conceptual model depicting the waste management core system and the enlarged system [15] 
are alternative solutions to the same problem, the functional units should be the same for all the scenarios. The primary functional unit of ORWARE is the management of waste from a certain area. Depending on the design of the scenarios, other functional units may be included, e.g. district heating, electricity, transport work and fertilisers. To ensure equal production of functional units in all scenarios, the system boundary is further enlarged to include compensatory processes that provide the functional units if necessary (Fig. 1).

As in standard LCA, the total outflow of emissions of the modelled system is quantified and the potential environmental impact is assessed by classification and characterisation of emissions into environmental impact categories. Impact categories include different impacts such as global warming, eutrophication, acidification and resource depletion in terms of primary energy consumption. Economic models are integrated within the process submodels, which calculate both financial costs and environmental costs in a form of simplified cost-benefit analysis. Since the economic analysis part puts a monetary value on the emissions quantified in the life cycle inventories and the impacts considered in the impact assessment, it is a LCC [20]. Further information on impact assessment and economic calculations in ORWARE can be obtained in [21,22].

The ORWARE model is built using MATLAB ${ }^{\circledR}$ with its graphical interface SIMULINK ${ }^{\circledR}$ [23]. The results of simulations are transferred to Microsoft Excel where diagrams discernible by decision-makers are made.

\section{Illustrating ORWARE as an environmental technology chain assessment tool}

In the following section, a previously done research is used to illustrate how ORWARE can be employed to analyse and compare systems of chains of technical processes designed to provide equal functions in different ways. This is further used as a basis for discussion of how the principles of ORWARE may provide a generic structure in what is here tentatively termed as environmental technology chain assessment since econ- omic analysis was not done. For this purpose specific results regarding the different technology chains are of less interest. Therefore, detailed descriptions of submodels and assumptions, which are important to assess the credibility of the results, are omitted. Only a short summary of the research design is provided.

Generally, studies with ORWARE have been designed primarily to evaluate different waste management options. In the study used as illustration here namely "Environmental Systems Analysis of Waste Management-Prospects of Hydrogen Production from Waste for Use in Fuel Cell Vehicles" [24], the focus was shifted to show equal interest in different options for fuelling vehicles, in this case a five-passenger taxi. The link between these two focus areas is found in the production of vehicle fuel using different waste treatment technologies. The scenarios represent alternative technology chains, including at the same time alternative waste treatment options and alternative vehicle fuelling options. This feature of the scenarios is important as it gives the opportunity to see the synergy of integrating the waste management and the transport sectors.

Four waste management scenarios, including incineration, anaerobic digestion and thermal gasification, were selected on the basis of possible future trends and the current practices. The same amount of waste is handled in all scenarios as depicted in Fig. 2 below. Three of these scenarios extend into the transportation sector through the production of waste-derived vehicle fuels, used in biogas vehicles and fuel cell vehicles (FCV). Incineration lacks the link to the transportation sector, whereby transportation is assumed to be provided by petrol-fuelled internal combustion engine vehicles (ICEV).

For the sake of comparability between scenarios, four functional units were defined:

1. Management of the total amount of biodegradable waste in Stockholm i.e. 72000 tons per year.

2. Production of a certain amount of district heating.

3. A certain transport work (distance travelled) by a five-passenger taxi.

4. Delivery of a certain amount of crop-available nitrogen and phosphorous.

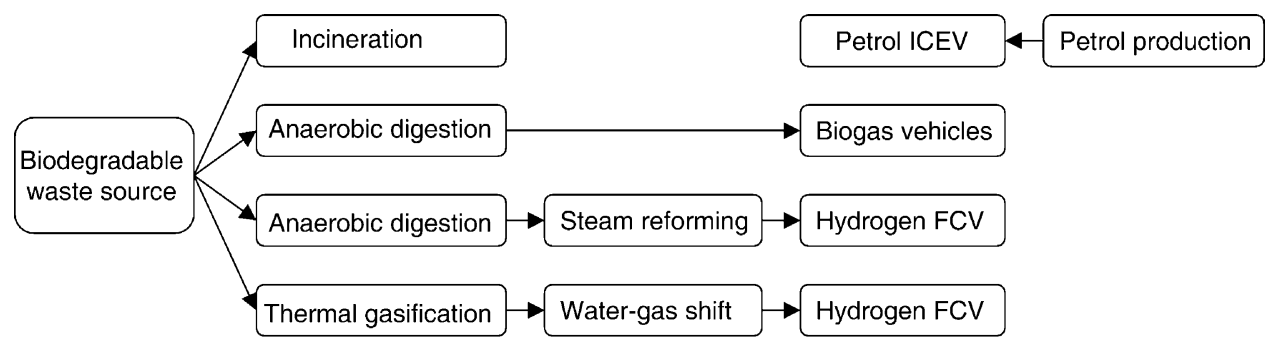

Fig. 2. Schematic presentation of the scenarios analysed. 
Management of the same amount of waste in all scenarios is ensured automatically by the design of the waste management scenarios. The size of the other functional units is determined by the maximum quantity recovered from the waste in any of the studied scenarios. To fulfil the functional units in the other scenarios, the functions are produced by compensatory processes that are added to the enlarged system model. Thus, the complete technology chain scenarios are as follows:

Scenario 1 Incineration. Petrol ICEVs. All biodegradable wastes are incinerated with recovery of heat and electricity, but no vehicle fuel recovery. Transport work is provided by petrolfuelled ICEVs.

Scenario 2 Anaerobic digestion. Biogas vehicles. All biodegradable wastes are treated by anaerobic digestion. Digester product is used as fertiliser, while reject from the anaerobic digester is incinerated. The generated biogas from the anaerobic digester is used to fuel biogas vehicles.

Scenario 3 Anaerobic digestion. Hydrogen FCVs. All biodegradable wastes are treated by anaerobic digestion. Digester product is used as fertiliser, while reject from the anaerobic digester is incinerated. The generated biogas is converted to hydrogen through steam reforming. The hydrogen is used in FCV.

Scenario 4 Thermal gasification. Hydrogen FCVs. All biodegradable wastes are treated by thermal gasification. The generated synthesis gas is converted to hydrogen through the water-gas shift reaction. The hydrogen is used in FCVs as in Scenario 3.

The compensatory and up-stream processes of the enlarged system tend to have large impact on the total system results. It is therefore important to be aware of the assumptions made regarding these processes. Scenario 1 relies entirely on petrol-fuelled ICEVs to provide transport work. Although not indicated in the scenario descriptions, minor amounts of petrol in ICEVs will also be required in scenarios that do not fulfil the maximum functional unit. In addition to compensatory transportation by petrol-fuelled ICEVs, compensatory district heating is produced in a biomass-fired plant ${ }^{1}$ and compensatory nitrogen and phosphorous are pro-

\footnotetext{
${ }^{1}$ Biomass is assumed to be the likely alternative fuel for production of district heating in Stockholm [25].
}

vided by mineral fertilisers. Coal condense power was chosen for up-stream electricity generation, as it is often the marginal production of electricity in Sweden. ${ }^{2}$

The scenarios were analysed and compared with each other in terms of gained transport work from waste-derived fuels, energy turnover and global warming potential. While it is possible to assess the economic aspects of the different scenarios, in this study priority is given to the environmental impacts related to the major global cycles and the consumption of primary energy. This is, by no means, to underestimate the economic impact of the technologies.

\section{Results}

As the main objective of this paper is to illustrate the prospects of ORWARE as a tool for environmental technology chain assessment, the results regarding specific impact categories are not thoroughly presented. Full report of the assessment and simulation results are published as M.Sc. thesis [24]. For the purpose of illustration of results, diagrams and figures of transport work, energy use and global warming potential are presented.

\subsection{Transport work}

As determined by the functional unit for transport work, each scenario provides the same distance travelled by an equivalent vehicle namely biogas cars fuelled by biogas from waste, FCVs fuelled by hydrogen from waste, or ICEVs fuelled by petrol (Table 1). To fulfil the functional unit Scenarios 2 and 4 also includes compensatory transportation by ICEVs to some extent.

The upper part of Table 1 lists the type and amount of vehicle fuel, if any, that is recovered from waste in each scenario, fuel efficiency of the vehicles and the corresponding transport work provided by the fuel. Most fuel (in MJ) is recovered as biogas in Scenario 2, but due to the high fuel efficiency of FCVs, more transport work is gained from hydrogen recovered in Scenarios 3 and $4 .^{3}$ Most transport work is gained in Scenario 3, which thus determines the functional unit of transportation, $14107 \mathrm{~km}$. The fuel efficiency in this scenario and the fourth scenario is based on the assumption that a five-passenger, mid-sized vehicle

\footnotetext{
${ }^{2}$ Coal condense power constitutes a minor part of the Swedish power mix and is among the first to be affected by marginal changes in electricity demand [26].

${ }^{3}$ The fuel efficiencies of the modelled biogas and petrol vehicles (4.0 and $2.5 \mathrm{MJ} / \mathrm{km}$, respectively) correspond to current vehicle performances. The fuel efficiency of the modelled FCV $(1.6 \mathrm{MJ} / \mathrm{km})$ does not correspond to what is currently attainable, but rather reflects the likely relative difference in fuel efficiency between advanced ICEVs and FCVs in the near future.
} 
Table 1

Amount of fuel recovered from waste, compensatory fuel required and corresponding transport work in the different scenarios

\begin{tabular}{lllll}
\hline & $\begin{array}{l}\text { Scenario 1 } \\
\text { Incineration } \\
\text { Petrol ICEV }\end{array}$ & $\begin{array}{l}\text { Scenario 2 } \\
\text { Anaerobic digestion } \\
\text { Biogas vehicle }\end{array}$ & $\begin{array}{l}\text { Scenario 3 } \\
\text { Anaerobic digestion } \\
\text { FCV }\end{array}$ & $\begin{array}{l}\text { Scenario } 4 \\
\text { Thermal gasification } \\
\text { FCV }\end{array}$ \\
\hline Fuel recovered from waste & - & Biogas & Hydrogen & Hydrogen \\
Fuel efficiency (MJ/km) & - & 4.0 & 1.6 & 1.6 \\
Amount recovered (MJ) & 0 & $27 \times 10^{7}$ & $23 \times 10^{7}$ & $21 \times 10^{7}$ \\
Corresponding transport work (km) & 0 & $6.9 \times 10^{7}$ & $14 \times 10^{7}$ & $13 \times 10^{7}$ \\
Compensatory fuel & Petrol & Petrol & - & Petrol \\
Fuel efficiency (MJ/km) & 2.5 & 2.5 & - & 2.53 \\
Corresponding amount of fuel required (MJ) & $36 \times 10^{7}$ & $19 \times 10^{7}$ & 0 & $3.2 \times 10^{7}$ \\
Transport work (km) & $14 \times 10^{7}$ & $7.4 \times 10^{7}$ & 0 & $1.2 \times 10^{7}$ \\
\hline
\end{tabular}

using direct hydrogen FC technology will be capable of meeting the US Department of Energy's Partnership for a New Generation of Vehicles (PNGV) goal of 80 miles per gallon equivalent (mpgeq) $(0.029 \quad 1 / \mathrm{km})$ $[22,27]$. A thorough analysis of the results from this illustration requires testing the validity of this assumption.

The lower part of Table 1 shows the compensatory fuel, if any, and a corresponding fuel efficiency. Petrol in ICEV acts as compensatory fuel. Also listed are the transport work and the corresponding amount of fuel required to fulfil the functional unit of transportation. The highest total fuel requirement appears in Scenario 2 , which relies both on biogas vehicles, the least fuelefficient vehicle and petrol ICEVs. Scenario 1 however requires more fossil fuel, as it is entirely dependent on petrol.

\subsection{Energy recovery and use}

In all the scenarios of alternative technology chains assessed, energy is recovered from waste in different forms: district heating, electricity and vehicle fuel (biogas and hydrogen). Energy is expended in collecting and treating the waste and mainly to fulfil the functional units of district heating, transportation and fertiliser. The net energy use of the total system is displayed in Fig. 3 in terms of primary energy including all energy use along the life cycle of an energy carrier.

Biomass constitutes a large part of the primary energy consumption in Scenarios 2-4 in order to fulfil the functional unit of heat production. Scenario 1 recovers most energy in the form of district heating and, thus, requires no compensatory heat production from biomass. Oil is consumed in all scenarios partly to provide diesel for waste collection but mainly to provide petrol for ICEVs in compensatory transportation. Consequently, Scenario 1, in which waste is incinerated and no vehicle fuel is recovered from waste, has the highest oil consumption. Scenario 3, with the highest gain of transport work from waste-derived vehicle fuel, consumes oil only to produce diesel for waste collection. Coal consumption occurring in all

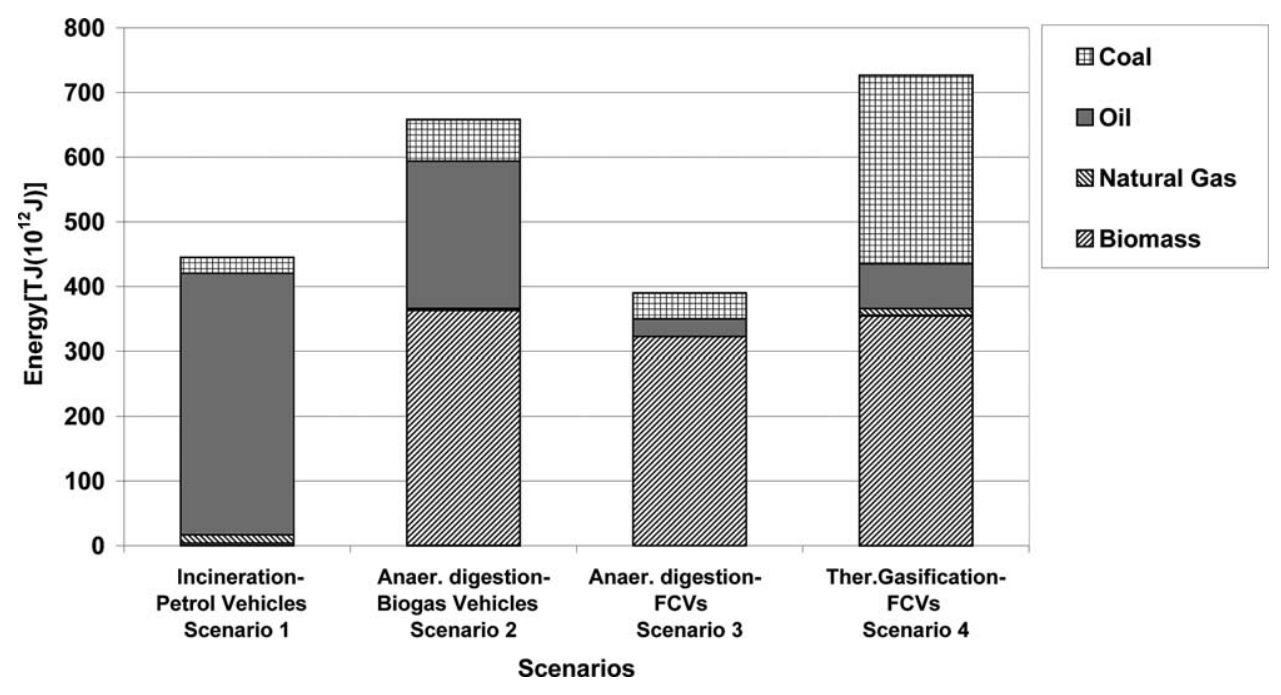

Fig. 3. Primary energy carriers of the total system divided over energy carriers. 


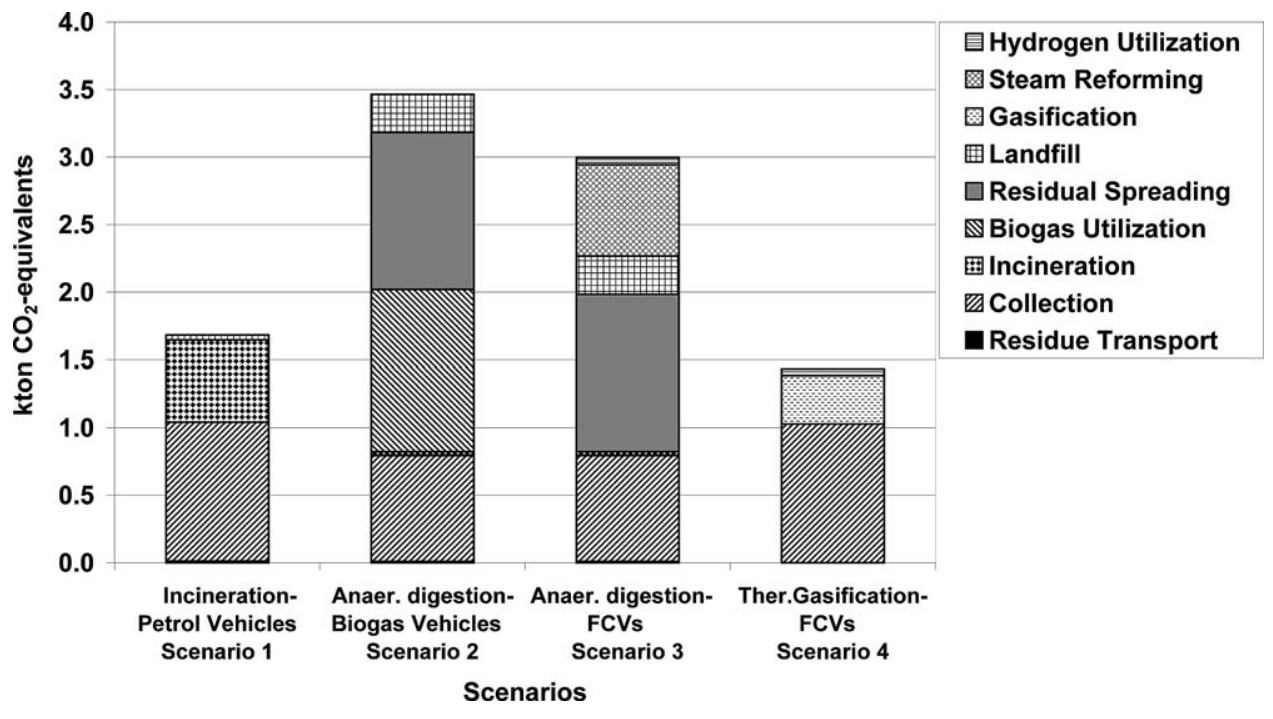

Fig. 4. GWP from the processes of the core system.

scenarios, is due to up-stream production of electricity. Thermal gasification in Scenario 4 apparently has a very high electricity load, a determining factor for the poor energy performance of this scenario.

Scenarios 1, 3 and 4 are roughly equally efficient in recovering energy from waste although in different forms. Therefore, they have similar energy requirements for compensatory processes (mainly biomass and oil), and their relative performances depend mostly on the energy use in the waste treatment processes. Scenario 2 is less efficient in recovering energy from waste, and thus has a larger burden of compensatory production. Scenarios 1 and 3 stand out as most energy efficient overall, as they both have efficient energy recovery from waste and low energy requirements for waste treatment.

However, in Fig. 3 all energy resources are represented equally, disregarding whether they are renewable or non-renewable. It may be argued that biomass as a renewable resource should not be valued on an equal basis as the non-renewable energy resources. If biomass were not counted at all, Scenario 3, which links anaerobic digestion and FCVs, would be the least energy consuming. Even in that case, thermal gasification in Scenario 4 would however still be the most energy consuming. It is quite clear that a shift to nonfossil based electricity generation would change the results in favour of thermal gasification. The performance of Scenario 3 highly depends on whether the fuel economy assigned to it would be realised or not.

\subsection{Global warming potential}

The model calculates the global warming potential (GWP) as the net potential impact caused by the greenhouse gases $\mathrm{CO}_{2}, \mathrm{CH}_{4}$ and $\mathrm{N}_{2} \mathrm{O}$ expressed as $\mathrm{CO}_{2}$ - equivalents. The figures below show the GWP from the core system (Fig. 4) and from the total system including the enlarged system (Fig. 5).

Considering only the core system, Scenarios 2 and 3 that involve anaerobic digestion show poor performance. Spreading of organic fertiliser and utilisation of biogas either directly in biogas cars or in FCVs via steam reforming, release significant amounts of greenhouse gases (Fig. 4).

However, when the total system is considered (Fig. 5), the impact is dominated by the compensatory and up-stream processes of the enlarged system. The major impact in Scenarios 1 and 2 is caused by compensatory petrol. Scenario 3 has the highest gain of transport work, and thus requires no compensatory petrol. Up-stream production of electricity used by thermal gasification dominates the impact in Scenario 4. Despite the significant energy requirements for compensatory heat production in Scenarios 2-4 (Fig. 3), this has no impact on GWP because biogenic $\mathrm{CO}_{2}$ is not counted as contributing to global warming. Apparently, compensatory production of mineral fertiliser is also of minor importance for this impact category. Overall, FCVs fuelled by hydrogen that is produced by steam reforming of biogas, represented by Scenario 3, appears to be the technology chain that is most efficient in minimising greenhouse gas emissions.

\section{Discussion and conclusion}

This section discusses and makes some concluding remarks concerning both the results obtained from the illustration and the use of ORWARE as a TA tool. 


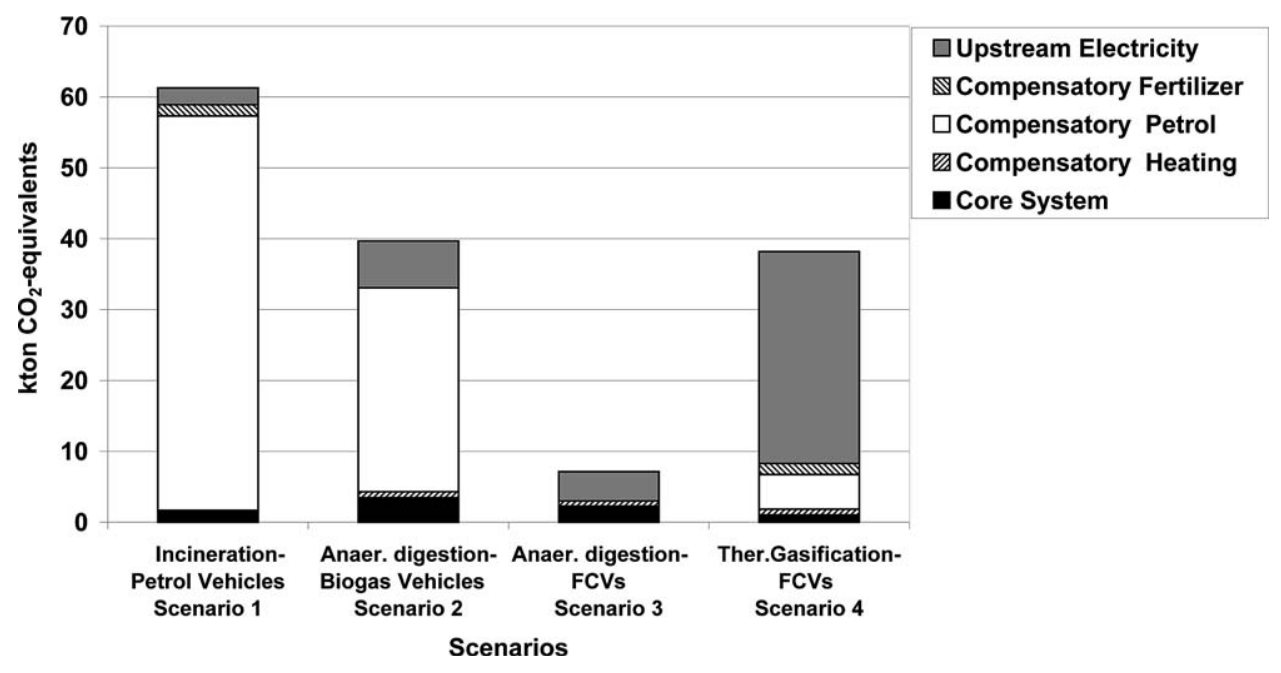

Fig. 5. GWP from the total system.

\subsection{On results of illustration}

As can be seen from the results obtained, Scenario 3 is the most efficient scenario. In other words, it is better to use biogas to produce hydrogen for FCV in comparison with the less efficient use of biogas in Scenario 2.

Although somewhat more energy is recovered and less energy is used by core system in Scenario 1 (diagram not included in this paper), Scenario 3 uses less primary energy overall. This is due to the "quality" of the recovered energy, and is revealed by including the compensatory processes. Despite high recovery of hydrogen in Scenario 4, which is efficiently used in FCVs, electricity consumption in thermal gasification results in overall poor energy efficiency of this scenario. To make this technology chain more competitive and attractive, something must be done to reduce the electricity use. However, this process was designed to favour low emission levels from the facility, which is not reflected by the impact categories that we have evaluated.

Regarding the environmental impacts since biomass does not contribute to GWP, the trend is quite different compared to energy consumption. Hence, the results would look different if for instance a non-renewable energy source were assumed for compensatory district heating.

While recognising the uncertainties associated with the data used and assumptions put up, the results obtained can be used as a good starting point for ameliorating the unestablished technologies of steam reforming of biogas and thermal gasification of waste. The results obtained if reinforced by further studies would contribute in pulling up the technologies into the market. Taking all impact categories as equally important, the processes of converting biogas into hydrogen and gasifying the organic waste and sub- sequent conversion to hydrogen for use in FCVs have rich environmental prospects.

By including the compensatory processes in the total system model, system-wide impacts are revealed. Without this perspective, one could miss important differences, such as Scenario 3 being more energy efficient than Scenario 1, although it is less energy efficient in the core system. However, this perspective also introduces additional uncertainty in the model, but it is necessary in order to promote discussions regarding system-wide impacts.

It should be noted that there was no weighting done during the course of the work and the results should be seen only from a wider perspective.

\subsection{On illustrating ORWARE vs. TA}

At the conceptual level, the different areas of impacts addressed by conventional TA can be re-categorised into ecological, economic and social categories.

ORWARE as an aid to environmental technology chain assessment tool is demonstrated as applied to the link between the waste management and the transport sector, but the same principle can be used to model other technical systems. The same modelling concept can be applied to address major ecological impacts and the economic implications. On the other hand, since the same principle can not be used to include social effects, the possibility of incorporating a list of indicators should be examined.

The problem of "non-paradigmatic" and "noncumulative" feature of TA mentioned in Brooks [7] can be remedied by using a tool like ORWARE at the right place in the broad spectrum of TA platform, the impact assessment part of conventional TA. This is because ORWARE is founded on well-established concepts and standard tools namely MFA/SFA, LCA and 
LCC that cross fertilise each other. It has a promising potential of enhancing the environmental, resource use and economic dimensions of the assessment works of the conventional TA.

Once simulation is done, the results of assessment are available and hence the whole work of assessment including developed submodels and simulation results provide a library of knowledge that can be accumulated, retrieved, processed and used.

Armstrong and Harman [6] after discussing different definitions and exercises of TA observed that a useful TA should produce a comprehensive, even-handed evaluation and comparison of the valid alternative choices. The requirement of being comprehensive should be looked at as implying both addressing as many aspects as possible and being comprehensive within each aspect assessed. The systems perspective and the combination of core system and compensatory systems in ORWARE give the opportunity to have insight into different sectors simultaneously and help understand how they influence each other. It is important to use the systems perspective in ORWARE as a TA tool means for analysing more than an isolated piece of technology [28]. It helps identify issues that were not recognisable before.

Even-handed assessment is important in different ways such as reproducibility, reliability, credibility, etc. An assessment work could suffer from being not evenhanded because of factors such as the type of approach used. Conventional TA relied on own judgements and intuition of the assessors.

A computer-based tool such as ORWARE provides an even-handed assessment and structured handling of input and output data that cover ecological and economic parameters. This permits consistent and coherent technology assessments. Using quantitative analysis as in ORWARE makes comparison and addition of values across chain of technologies easier instead of using such ambiguous and subjective terms as "significant impact" and "slight increase" [6].

From the point of view of discussions on TA types with different starting points, ORWARE lies between the problem-induced TA and technology-induced TA.

As a last remark, ORWARE is not a remedy to all ills of TA-related tools and methodologies but it can definitely improve important parts of the assessment of technologies that we need to carry out more than ever before in our journey to sustainable development.

\section{Acknowledgements}

The authors would like to thank STEM (Swedish Energy Administration) who financed the research project "Prospects of Hydrogen Production from Waste for use in Fuel Cell Vehicles", the results of which are used as an illustration in this article.

\section{References}

[1] CEFIC. Technology assessment: a tool towards sustainable chemical industry. Brussels: European Chemical Industry Council; 1997 [Available from: http://www.cefic.be/position/st/ pp_st03.htm, August 2000].

[2] Ludwig B. The concept of technology assessment-an entire process to sustainable development. Sustainable Development 1997;5:111-7.

[3] van Eijndhoven JCM. Technology assessment: product or process. Technological Forecasting and Social Change 1997;54: 269-286.

[4] Wood FB. Lessons in technology assessment: methodology and management at OTA. Technological Forecasting and Social Change 1997;54:145-62.

[5] Durbin PT, Rapp F. Philosophy and technology. Boston: D. Reidel Publishing Company; 1983.

[6] Armstrong JE, Harman WW. Strategies for conducting technology assessments. Colorado: Westview Press; 1980.

[7] Brooks H. Technology assessment. In: Salomon J-J, Sagasti FR, Sachs-Jeantet C, editors. The uncertain quest science, technology and development. Tokyo, Japan: United Nations University Press; 1994.

[8] Rossini FA, Porter AL, Kelley P, Chubin DE. Framework and factors affecting integration within technology assessments. Atlanta: Georgia Institute of Technology; 1978.

[9] Wad A, Radnor M. Technology assessment: review and implications for developing countries. Science Policy Studies and Documents 1984;63.

[10] Blair PD. Technology assessment—current trends and the myth of a formula; 1994. Available from: http://www.wws.princeton.edu/ ota/ns20/blair_f.html, last accessed December 2001.

[11] BergIV M. Technology assessment in Europe: a documentation of TA research establishments. Karlsruhe: Kernforschungszentrum Karlsruhe; 1994.

[12] van Den Ende J, Mulder K, Knot M, Moors E, Vergragt P. Traditional and modern technology assessment: toward a toolkit-a research methodology and learning strategy for social impact assessment. Technological Forecasting and Social Change 1998;58:5-21.

[13] UNEP. Environmental technology assessment. United Nations Environmental Program; 2001. Available from: http://www.unep.or.jp/ietc/supportingtools/enta/, last accessed December 2001.

[14] Eriksson O, Frostell B, Björklund A, Assefa G, Sundqvist J-O, Granath J, et al. ORWARE - a simulation tool for waste management. Resources, Conservation and Recycling 2002;36: 287-307.

[15] Wrisberg N, Gameson T, editors. CHAINET definition document: European network on chain analysis for environmental decision support. Leiden: CML, Leiden University; 1998.

[16] Udo de Haes H, van der Voet E, Klein R. Substance flow analysis (SFA), an analytical tool for integrated chain management. Proceedings of the ConAccount Workshop Paradigm to Practice, Leiden, 21-23 January 1997. 1997.

[17] van der Voet E, Klein R, van Oers L, Heijungs R, Huele R, Mulder P. Substance flow analysis through the economy and the environment. Part I: system definition. Environmental Science and Pollution Research 1995;2(2):89-96.

[18] ISO. Environmental management-life cycle assessment-principles and frame work. Brussels: European Committee for Standardisation CEN; 1997 [ISO 14040:1997]. 
[19] ISO. Environmental management-life cycle assessment-goal and scope definition and inventory analysis. Brussels: European Committee for Standardisation CEN; 1998 [ISO 14041:1998].

[20] Wrisberg N, Udo de Haes HA, Bilitewski B, Bringezu S, BroRasmusse F, Clift R, et al. Demand and supply of environmnetal information. Wrisberg N, Udo de Haes HA, editors. Analytical tools for environmental design and management in a systems perspective. The combined use of tools. Boston: Kluwer Academic Publishers; 2002.

[21] Björklund A. Environmental systems analysis of waste management. Experiences from applications of the ORWARE model. Doctoral thesis. TRITA-KET-IM 2000:15. Stockholm: Department of Chemical Engineering and Technology, Division of Industrial Ecology, Royal Institute of Technology; 2000.

[22] Sundqvist J-O, Baky A, Björklund A, Carlsson M, Eriksson O, Frostell B, et al. Systems analysis of energy recovery from waste-evaluation of energy, environment and costs. Overview Report (in Swedish). IVL Report 1379. Stockholm: Swedish Environmental Research Institute; 2000.
[23] The Maths Works Inc. Simulink user's guide. Massachusetts, USA: Natick; 1993.

[24] Assefa G. Environmental systems analysis of waste management. Prospects of hydrogen production from waste for use in fuel cell vehicles. Masters thesis. TRITA-KET-IM 2000:3. Stockholm: Department of Chemical Engineering and Technology, Division of Industrial Ecology, Royal Institute of Technology; 2000.

[25] Birka Energy. Personal communication; 2000.

[26] STEM. Energy in Sweden. Swedish National Energy Administration; 2000.

[27] Björklund A, Melaina M, Keoleian G. Hydrogen as a transportation fuel produced from thermal gasification of municipal solid waste: an examination of two integrated technologies. International Journal of Hydrogen Energy 2001;26:1209-21.

[28] Henriksen ADP. A technology assessment primer for management of technology. International Journal of Technology Management 1997;13(5/6):615-38. 